\title{
A CORRELATIVE STUDY OF THE CARDIAC OUTPUT AND THE HEPATIC CIRCULATION IN HYPERTHYROIDISM ${ }^{1}$
}

\author{
By J. D. MYERS, E. S. BRANNON, AND B. C. HOLLAND \\ (From the Department of Medicine, Duke University School of Medicine, Durham, North \\ Carolina, and Emory University School of Medicine, Atlanta, Georgia)
}

(Submitted for publication March 24, 1950; accepted, May 8, 1950)

Controversy exists as to the status of the liver in hyperthyroidism in man. Clinical evidence of hepatic insufficiency is found in only the severest and most protracted cases. However, laboratory studies have demonstrated decreased bromsulphalein excretion (1), decreased hippuric acid synthesis (2), and diminished concentration of serum proteins particularly with reduction in serum albumen (3). Needle biopsy of the liver in a series of patients with usual degrees of thyrotoxicosis failed to demonstrate significant hepatic lesions (4). On the other hand, pathological study of the livers of subjects with fatal hyperthyroidism has quite regularly shown simple atrophy, congestion of sinusoids, and fatty metamorphosis (58). In many instances, necrosis of hepatic cells of a focal or centro-lobular distribution and even a moderate degree of cirrhosis as evidenced by fibrosis, lymphoid infiltration, and bile duct proliferation, have been found. An extensive centrolobular necrosis of the liver has been seen in some fatal cases. This lesion is comparable to the central necrosis produced in animals by a combination of excessive thyroid feeding together with anoxia (9), carbon tetrachloride intoxication (10), or infection $(11,12)$.

The status of the heart in hyperthyroidism is less controversial than that of the liver. Many investigators over the past four decades have found the cardiac output to be quite consistently elevated in uncomplicated hyperthyroidism (13). The full distribution of this increased minute output of the heart is of course not known but augmentation of the cutaneous blood flow (14) and the muscular flow of the forearm and calf $(15,16)$ has been demonstrated.

With the introduction of methods for $a$ ) the direct measurement of cardiac output and $b$ ) the estimation of the hepatic blood flow and splanchnic

1 This work was supported by grants from the Life Insurance Medical Research Fund and the Anna H. Hanes Fund of Duke University. oxygen consumption $(17,18)$, it became feasible to investigate the hepatic circulation in hyperthyroidism in man in correlation with the cardiac output. This report consists of such data collected on 14 subjects with thyrotoxicosis. In addition, data are recorded on 10 patients whose cardiac outputs were determined but in whom no studies of the hepatic circulation were made. Recordings of pressures in the right atrium, ventricle. and main pulmonary artery, and in a systemic artery were made in most of the subjects. In the first group of 14 , pressures in the large hepatic veins are also reported.

\section{METHODS}

Only patients with typical, unequivocal and uncomplicated hyperthyroidism as judged by symptoms, physical examination, and elevation of basal metabolic rate were chosen for this study. None had appreciable edema or proteinuria. All determinations were made after an overnight fast. Subjects were given either phenobarbital $90 \mathrm{mg}$. or sodium pentobarbital $100 \mathrm{mg}$. by mouth approximately an hour before the study. This sedation helped in performing the measurements without particular apprehension on the part of the subjects. It is our belief, with one exception (patient J. J., who became quite anxious during the study), that the observations were made under emotional conditions fully comparable to similar measurements in control subjects.

Most of the subjects had lost weight, as is to be expected in hyperthyroidism. The data herein reported are expressed in terms of square meters of body surface, estimated from height and actual body weight at the time of study. Correction of the surface area estimation by using ideal body weight instead of actual weight produces no significant change in the data or the conclusions drawn from them.

The hepatic blood flow was estimated by means of the bromsulphalein (BSP) technique of Bradley and associates, ${ }^{2}$ (17), utilizing catheterization of the hepatic

2 The validity of the bromsulphalein method for determining hepatic blood flow has recently been contested on the basis that there is significant extra-hepatic loss of the dye $(19,20)$. That there is no significant loss of BSP in the distribution of the inferior vena cava below the hepatic veins at the plasma concentration at which 
veins. Particulars of the method are found in previous publications $(18,21)$. Hematocrits were corrected by the factor 0.915 as suggested by Chapin and Ross (22). Cardiac outputs were measured by the direct Fick method with the mixed venous blood sample being collected through the catheter in the pulmonary artery, or in a few instances, for technical reasons, from the right ventricle or right atrium near the tricuspid valve. In eight of the 14 patients, the cardiac output was determined immediately prior to moving the catheter to an hepatic vein for estimation of hepatic blood flow; in the remaining six subjects, the cardiac output was measured immediately after the hepatic blood flow. Pressures from the right heart, pulmonary artery, femoral or brachial artery, and hepatic veins were recorded by means of the Hamilton manometer. Mean pressures were determined by planimetric integration.

\section{RESULTS}

The data on cardiac output and hepatic blood flow on the 14 patients with active hyperthyroidism and on two patients whose thyrotoxicosis had been completely controlled clinically with iodine and propylthiouracil are listed in Table I. Mean figures of the measurements in active hyperthyroidism are compared with mean data for a group of control subjects without significant disease who were studied in our laboratory under identical circumstances. These control subjects had a mean elevation in metabolic rate during the study of +9 per cent above the normal basal in contrast to $a+54$ per cent elevation in the hyperthyroids.

we work (usually 0.75 to $3 \mathrm{mg}$. per $100 \mathrm{ml}$.) is evidenced by the fact that in 20 determinations on eight subjects, the BSP concentration in inferior vena caval blood averaged $1.27 \pm 0.55 \mathrm{mg}$. per cent* whereas the simultaneous concentration in arterial blood averaged $1.28 \pm$ $0.55 \mathrm{mg}$. per cent. Urinary loss usually comprised about 3 per cent of the total dose infused and may therefore be disregarded. Concentrations of BSP in blood from the superior vena cava are slightly in excess of simultaneous arterial concentrations, due to dye being added to the superior caval circulation via the infusion in an arm vein. Successive determinations of hepatic blood flow at plasma BSP concentrations progressing from $1 \mathrm{mg}$. per cent to as high as $6 \mathrm{mg}$. per cent in control subjects uniformly gave essentially identical estimations of hepatic blood flow at all plasma levels. This is evidence against appreciable extra-hepatic loss of dye even at these quite high blood concentrations. We must conclude that, as physiological measurements go, the BSP method gives a valid estimate of hepatic blood flow. Furthermore, the estimation of the hepatic blood flow in control subjects by a completely different method (18) gave results which agreed closely with the BSP procedure.

\footnotetext{
* The \pm value is the standard deviation.
}

Thus the controls are adequately basal to supply a good baseline for comparison with the results in hyperthyroidism.

As compared to control individuals, relatively higher arterial concentrations of BSP were obtained in patients with hyperthyroidism for a given dose of the dye. The 14 patients obtained a mean concentration in arterial plasma of $1.83 \pm 0.39$ $\mathrm{mg} .{ }^{3}$ per $100 \mathrm{ml}$. from an average infusion rate of $2.49 \pm 0.16 \mathrm{mg}$. per min. Fifty control subjects achieved a mean arterial concentration of $1.45 \pm 0.08 \mathrm{mg}$. per $100 \mathrm{ml}$. from an average infusion rate of $3.15 \pm 0.07 \mathrm{mg}$. per min.

The excretion of BSP by the liver under the conditions of this study involves three variables: the arterial concentration of $\mathrm{BSP}$; the hepatic arteriovenous difference of BSP; and the hepatic plasma flow. The percentage extraction of BSP [ (arterial plasma concentration - hepatic venous plasma concentration $) \div$ (arterial plasma concentration)] involves the first two of these variables. The percentage extraction was significantly decreased $(p<0.01)$ in subjects with hyperthyroidism, they averaging $36.9 \pm 5.9$ per cent extraction as compared to $52.0 \pm 2.0$ per cent for the controls. The percentage extraction, however, at a given rate of hepatic plasma flow varies inversely with the arterial concentration. The slight difference in mean arterial concentration of BSP in the two groups does not appear adequate to account for the more substantial difference in extraction. From our data, the control subjects at an arterial concentration of $1.83 \mathrm{mg}$. per $100 \mathrm{ml}$. (the average arterial concentration for the group with thyrotoxicosis) would have a predicted extraction of 46 per cent, to be compared with the 37 per cent extraction actually found in the hyperthyroid group at that average arterial concentration.

The rate of excretion of bromsulphalein equals the product of hepatic plasma flow and the hepatic arteriovenous difference of dye. The expression, then, of bromsulphalein excretion in terms of BSP clearance: [ (total removal rate of BSP in mg. per min. per sq. M.) $\div$ (concentration of $\mathrm{BSP}$ in $\mathrm{mg}$. per $\mathrm{ml}$. of arterial plasma) $=\mathrm{ml}$. of arterial plasma cleared completely of BSP per min. per sq. M.] involves all three of the above

\footnotetext{
${ }^{3}$ Hereafter, throughout the paper, \pm values represent standard errors.
} 


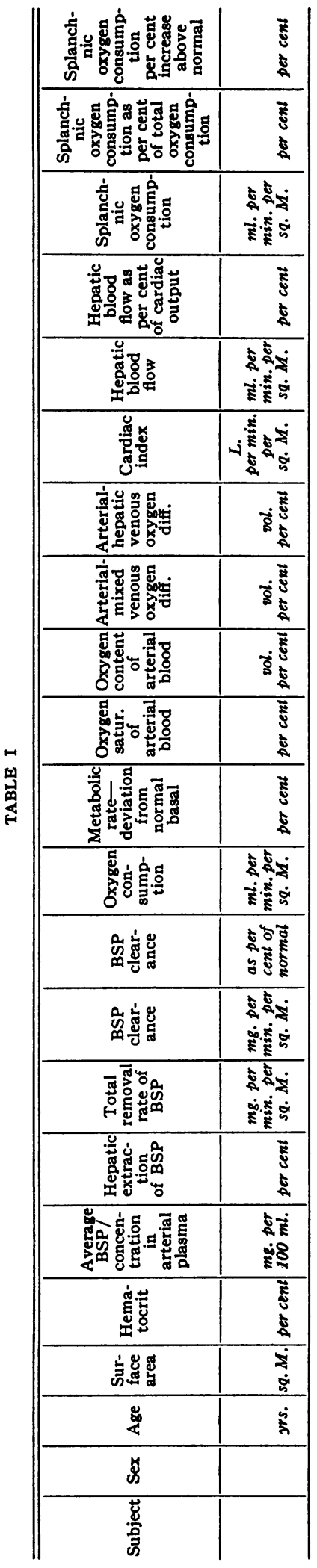

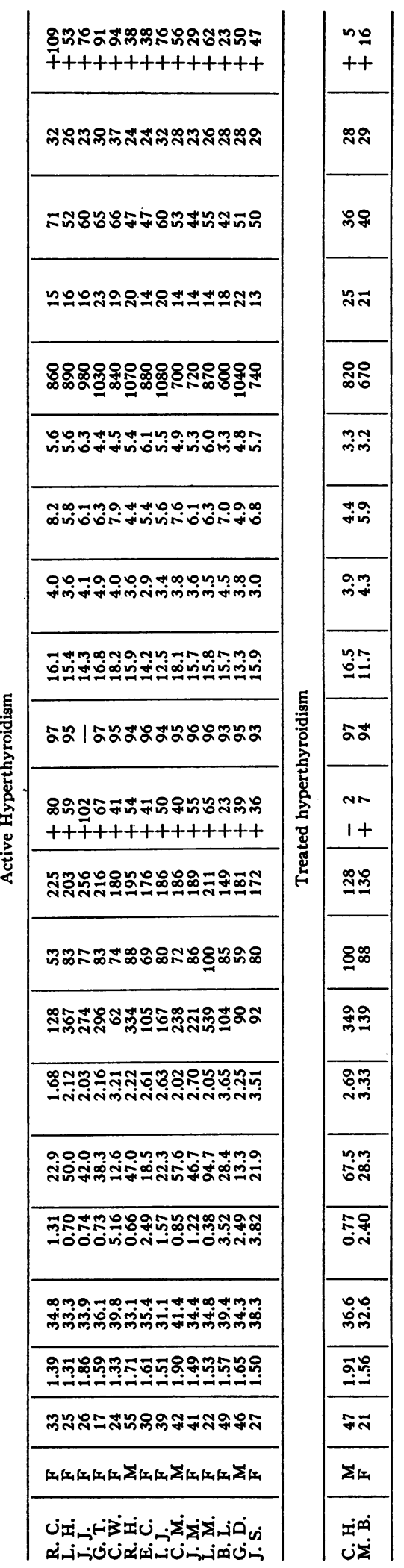


variables and is superior to expression of excretion as percentage extraction. BSP clearances are best stated as percentages of normal in order to correct for the varying arterial concentrations of dye. The mean BSP clearance for the 14 subjects with thyrotoxicosis was $78 \pm 3$ per cent of normal with a range of from 53 to 100 per cent. Thus the decreased percentage extraction found in hyperthyroidism is not adequately compensated in general by the somewhat higher hepatic blood flows of this disease (see below). It must be concluded that some individuals with thyrotoxicosis have a mild to moderate disability in excreting bromsulphalein.

None of the hyperthyroid patients had a significant degree of unsaturation of the arterial blood for oxygen. Likewise, none had a degree of anemia, as evidenced by the values for hematocrit and oxygen content of arterial blood, which per se would be expected to alter cardiac output or hepatic blood flow $(23,24)$.

The arterial-mixed venous oxygen differences ranged from 2.9 to 4.9 volumes per cent in the patients with hyperthyroidism and from 2.8 to 5.2 volumes per cent in the controls. The mean oxygen differences are essentially identical-3.76 \pm 0.14 volumes per cent in hyperthyroids versus $3.84 \pm 0.16$ volumes per cent in normals. The elevated total oxygen consumptions in the sub- jects with thyrotoxicosis in the presence of normal arterial-mixed venous oxygen differences yield elevated cardiac outputs for most of the thyrotoxics when these are calculated by the Fick principle. The range of cardiac index (cardiac output in L. per min. per sq. M. of body surface) in hyperthyroidism was from 3.3 to 6.3 with a mean of $5.24 \pm 0.21 \mathrm{~L}$., to be compared with a mean value of $3.97 \pm 0.17 \mathrm{~L}$. for 15 controls who ranged from 2.5 to 4.9 . Statistically, the group with hyperthyroidism had definitely elevated cardiac outputs as compared with the controls $(p<0.01)$. This is the expected finding in accordance with the conclusions of many previous workers (13).

The ten subjects with hyperthyroidism shown in Table II had cardiac outputs measured by one of us (E. S. B.) at Grady Hospital in Atlanta prior to the correlative study of hepatic blood flow with cardiac output. The range of arterial-mixed venous oxygen differences in this group was from 2.5 to 4.7 volumes per cent with a mean of $3.87 \pm$ 0.19 . Cardiac indices varied from 3.9 to $8.3 \mathrm{~L}$. with an average of $5.87 \pm 0.40$. These figures compare favorably with the results in the Duke series in Table I, and, like the latter, differ significantly from control data. The somewhat higher mean cardiac index in the Grady series is to be expected because of the higher mean metabolic rate in that group, which was +72 per cent

TABLE II

Grady series

\begin{tabular}{|c|c|c|c|c|c|c|c|c|c|c|c|c|c|c|c|c|c|}
\hline \multirow{2}{*}{ Subject } & \multirow{2}{*}{ Sex } & \multirow{2}{*}{ Age } & \multirow{2}{*}{$\begin{array}{l}\text { Sur- } \\
\text { face } \\
\text { area }\end{array}$} & \multirow{2}{*}{$\begin{array}{l}\text { Hem- } \\
\text { atocrit }\end{array}$} & \multirow{2}{*}{$\begin{array}{c}\text { Oxygen } \\
\text { consump. }\end{array}$} & \multirow{2}{*}{$\begin{array}{c}\text { Meta- } \\
\text { bolic } \\
\text { rate } \\
\text { devia- } \\
\text { tion } \\
\text { from } \\
\text { normal } \\
\text { basal }\end{array}$} & \multirow{2}{*}{$\begin{array}{l}\text { Arterial } \\
\text { oxygen } \\
\text { content }\end{array}$} & \multirow{2}{*}{$\begin{array}{c}\text { Arterial } \\
\text { mixed } \\
\text { venous } \\
\text { oxygen } \\
\text { diff. }\end{array}$} & \multirow{2}{*}{$\begin{array}{c}\text { Cardiac } \\
\text { index }\end{array}$} & \multirow{2}{*}{$\begin{array}{l}\text { Pulse } \\
\text { rate }\end{array}$} & \multirow{2}{*}{$\begin{array}{l}\text { Stroke } \\
\text { volume }\end{array}$} & \multicolumn{3}{|c|}{$\begin{array}{c}\text { Femoral arterial } \\
\text { pressure }\end{array}$} & \multirow{2}{*}{$\begin{array}{l}\text { Periph- } \\
\text { eral } \\
\text { resist- } \\
\text { ance }\end{array}$} & \multirow{2}{*}{$\begin{array}{c}\text { Mean } \\
\text { right } \\
\text { atrial } \\
\text { pressure }\end{array}$} & \multirow{2}{*}{\begin{tabular}{|c} 
Right \\
ventric \\
ular \\
systolic \\
pressure
\end{tabular}} \\
\hline & & & & & & & & & & & & Syst. & Diast. & Mean & & & \\
\hline $\begin{array}{l}\text { D. H. } \\
\text { C. D. } \\
\text { H. H. } \\
\text { B. E. } \\
\text { J.F. } \\
\text { T. M. } \\
\text { S. M. } \\
\text { J.M. } \\
\text { W. D. } \\
\text { J. P. }\end{array}$ & $\begin{array}{l}\mathbf{M} \\
\mathbf{M} \\
\mathbf{F} \\
\mathbf{F} \\
\mathbf{F} \\
\mathbf{F} \\
\mathbf{M} \\
\mathbf{F} \\
\mathbf{M} \\
\mathbf{M}\end{array}$ & \begin{tabular}{|c|}
$y r s$. \\
44 \\
59 \\
24 \\
22 \\
12 \\
27 \\
31 \\
26 \\
58 \\
35
\end{tabular} & $\begin{array}{l}\text { sq. } M . \\
1.72 \\
1.71 \\
1.44 \\
1.61 \\
1.43 \\
1.52 \\
1.89 \\
1.42 \\
1.75 \\
1.75\end{array}$ & \begin{tabular}{|c|} 
per cent \\
35.1 \\
27.5 \\
35.6 \\
29.9 \\
35.5 \\
34.8 \\
38.9 \\
36.6 \\
42.1 \\
43.9
\end{tabular} & $\begin{array}{c}\text { ml. per } \\
\text { min. per } \\
\text { sq. M. } \\
213 \\
256 \\
197 \\
219 \\
226 \\
194 \\
243 \\
227 \\
262 \\
181\end{array}$ & $\begin{array}{l}\text { per cent } \\
+64 \\
+106 \\
+57 \\
+74 \\
+52 \\
+56 \\
+80 \\
+83 \\
+111 \\
+36\end{array}$ & 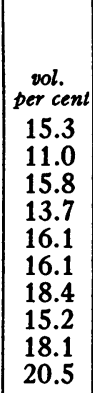 & \begin{tabular}{|c|} 
vol. \\
per cent \\
4.7 \\
3.5 \\
4.4 \\
4.0 \\
3.2 \\
2.8 \\
4.1 \\
3.8 \\
3.6 \\
4.6
\end{tabular} & 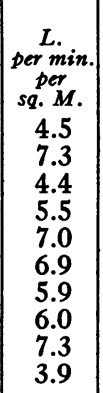 & \begin{tabular}{|c} 
per \\
min. \\
92 \\
91 \\
92 \\
84 \\
84 \\
124 \\
94 \\
116 \\
107 \\
107 \\
110
\end{tabular} & 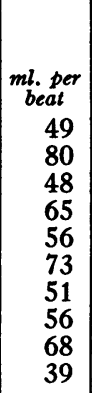 & \begin{tabular}{|c}
$\underset{\mathrm{mm} .}{\mathrm{Hg}}$ \\
133 \\
158 \\
160 \\
152 \\
143 \\
153 \\
144 \\
153 \\
132
\end{tabular} & $\begin{array}{c}\underset{\mathrm{mm}}{\mathrm{mg}} \\
69 \\
60 \\
63 \\
68 \\
73 \\
83 \\
73 \\
71 \\
80\end{array}$ & $\begin{array}{r}\underset{H \boldsymbol{H}}{\mathrm{m}} \\
91 \\
96 \\
92 \\
93 \\
101 \\
105 \\
101 \\
98 \\
98\end{array}$ & $\begin{array}{c}\text { mm. Hg } \\
\text { per L. } \\
\text { per min. } \\
\text { per } \\
\text { sq. M. } \\
20.2 \\
11.8 \\
20.9 \\
16.9 \\
\frac{}{14.6} \\
18.0 \\
16.8 \\
13.4 \\
25.1\end{array}$ & \begin{tabular}{|c|}
$m m . \mathrm{Hg}$ \\
3 \\
3 \\
2 \\
5 \\
3 \\
3 \\
2 \\
$\frac{2}{3}$ \\
1
\end{tabular} & $\begin{array}{c}m m . H g \\
33 \\
54 \\
40 \\
43 \\
38 \\
37 \\
35 \\
40 \\
44 \\
40\end{array}$ \\
\hline $\begin{array}{l}\text { Mean } \\
\text { S.D. } \\
\text { S.E. }\end{array}$ & & & & & & $\begin{array}{l}+72 \\
\pm \quad 24 \\
\pm \quad 8\end{array}$ & & $\begin{array}{r}3.87 \\
\pm 0.61 \\
\pm 0.19\end{array}$ & $\begin{array}{r}5.87 \\
\pm 1.27 \\
\pm 0.40\end{array}$ & & $\begin{array}{r}58 \\
\pm 13 \\
\pm 4\end{array}$ & & & $\begin{array}{r}96 \\
\pm 6 \\
\pm 2\end{array}$ & $\begin{array}{r}17.5 \\
\pm 4.2 \\
\pm 1.4\end{array}$ & $\begin{array}{r}2.8 \\
\pm 1.1 \\
\pm 0.4\end{array}$ & $\begin{array}{r}40.4 \\
\pm \quad 5.9 \\
\pm \quad 1.9\end{array}$ \\
\hline
\end{tabular}


as compared to the mean of +54 per cent in the Duke series.

The situation in respect to arterial-hepatic venous oxygen differences in hyperthyroidism is quite different from that with arterial-mixed venous oxygen differences. Whereas the arterialhepatic venous oxygen difference in 49 controls ranged from 3.1 to 6.2 volumes per cent with a mean of $4.29 \pm 0.11$, the hyperthyroid patients varied from 4.4 to 8.2 volumes per cent for a mean of $6.31 \pm 0.30$. Since the difference between these means is again highly significant statistically ( $p<0.01$ ), it can be said that in general hyperthyroidism is associated with a high degree of extraction of oxygen from the blood perfusing the splanchnic area, including the liver.

The estimated hepatic blood flows vary over a considerable range in both the control and hyperthyroid groups. This is explainable, at least in part, when it is remembered that the flow through only one portion of the liver is being determined in each case, and that flows as estimated from several areas of the liver under the same conditions may show considerable variation (17). The hepatic blood flows for the 14 subjects with hyperthyroidism ranged from 600 to $1,080 \mathrm{ml}$. per min. per sq. M. of body surface; 53 controls gave values of from 490 to $1,190 \mathrm{ml}$. The average values are in hyperthyroidism $-879 \pm 40 \mathrm{ml}$., and for the controls $812 \pm 24 \mathrm{ml}$., the small difference between the means not being significant $(p=0.2)$. When the hepatic blood flow for each individual in the two groups is expressed as a percentage of the corresponding cardiac output, one finds, for the 15 control subjects on whom both hepatic blood flow and cardiac output were measured, that the hepatic blood flow comprises on the average $19 \pm 1$ per cent of the total cardiac output. The corresponding figure for the 13 thyrotoxic patients is $17 \pm 1$ per cent.

Since the individuals with hyperthyroidism have at the same time $a$ ) normal or slightly supernormal hepatic blood flows and $b$ ) elevated arterial-hepatic venous oxygen differences, it is obvious that they have splanchnic oxygen consumptions in excess of normal. Actually, all but two of the 14 hyperthyroids had splanchnic oxygen consumptions which exceeded the upper limit of the control range ( $46 \mathrm{ml}$. per min. per sq. M.) and all of the 14 were well above the control mean of $34 \pm 1 \mathrm{ml}$. The patients with hyperthyroidism ranged from 42 to $71 \mathrm{ml}$. per min. per sq. M. for a mean of $54 \pm 2.4 \mathrm{ml}$, a highly significant rise above the control. When the splanchnic oxygen consumptions for the two groups are expressed in percentages of the respective total oxygen consumptions, values are obtained of $28 \pm 1$ per cent for the thyrotoxics and of $23 \pm 1$ per cent for the controls. In view of the relatively narrow range of the values for both groups, the difference between the means proves statistically significant $(p<0.01)$. This finding indicates that splanchnic metabolism, which in the resting and fasting state is presumably largely hepatic metabolism, is increased not only in proportion to the increase in overall bodily metabolism, but even in excess of the latter. This is supported by the fact that the splanchnic oxygen consumption in the 14 patients with hyperthyroidism was increased to +60 per cent over the normal splanchnic oxygen consumption whereas the concomitant increase in total oxygen consumption was only 45 per cent (54 per cent minus 9 per cent).

The two subjects with previous, typical thyrotoxicosis, whose disease had been clinically controlled by the use of propylthiouracil and iodine, yielded results which did not differ in any way from the control results. Thus far we have not had the opportunity to study the hepatic circulation in a given patient before and after hyperthyroidism has been successfully treated.

Data abstracted from the recordings of arterial, right heart, and hepatic venous pressures in both the Duke and Grady series are given in Tables II and III. The control values shown are all from our own laboratories, including the reports of Stead and colleagues (25), and Hickam and Cargill (26).

Most of the patients with hyperthyroidism had the expected tachycardia. With but few exceptions, the increase in pulse rate paralleled the increase in cardiac output so that the mean stroke volume for the 21 patients, $54 \pm 3 \mathrm{ml}$. per beat per sq. M. of body surface, did not differ significantly $(p=0.2)$ from the mean value of $49 \pm 2 \mathrm{ml}$. of Stead and associates.

The mean femoral arterial pressure in the 20 hyperthyroid patients in whom it was measured averaged $98 \pm 3 \mathrm{~mm}$. Hg in comparison to Stead's mean of $85 \pm 2$. The average age of the hyper- 


\begin{tabular}{|c|c|c|c|}
\hline מִּ & & 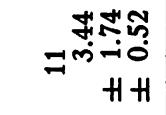 & 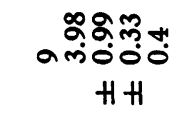 \\
\hline$n=$ & & 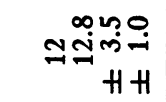 &  \\
\hline$-\infty$ & &  & 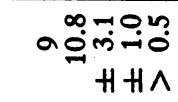 \\
\hline กิ & &  & 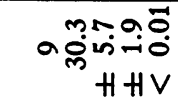 \\
\hline 음 & &  & 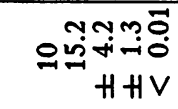 \\
\hline సి & & 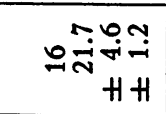 &  \\
\hline$\rightarrow+$ & 鄫 & 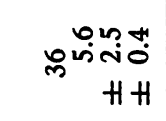 & 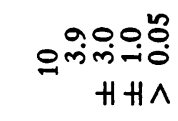 \\
\hline Ho & 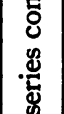 & 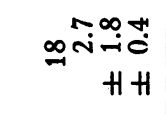 & 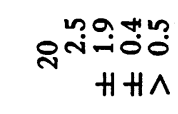 \\
\hline 串 & 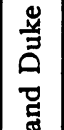 & $\begin{array}{r}\underset{\sim}{\sim} \underset{\sim}{\infty}{ }^{\infty} \\
H\end{array}$ & $\begin{aligned} \Rightarrow & \Rightarrow m=0 \\
& H+0^{n}\end{aligned}$ \\
\hline त्ञ & 㔺 & 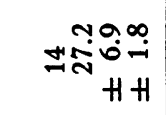 & 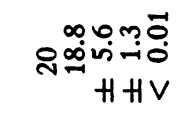 \\
\hline ஃిర్తి & 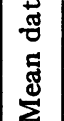 & $\begin{array}{r}\forall \infty a N \\
H H\end{array}$ & $\begin{array}{r}\overrightarrow{0} \\
\text { ลัammo } \\
\text { HHV }\end{array}$ \\
\hline$\stackrel{\infty}{\gtrless}$ & & & \\
\hline 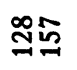 & & & \\
\hline F⿻上丨 & & 역요요 & 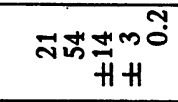 \\
\hline ๙న & & & \\
\hline mָ̃ & & \multirow{3}{*}{ 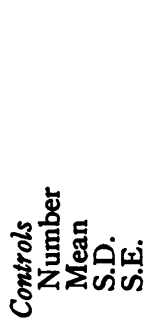 } & \multirow{3}{*}{ 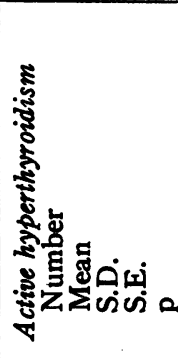 } \\
\hline $\begin{array}{l}\text { NR } \\
1+\end{array}$ & & & \\
\hline نં & & & \\
\hline
\end{tabular}


thyroid group, however, was 35.3 years, which is considerably higher than the 25.6 year average of Stead's group of healthy young men. The mean femoral arterial pressure in a group of 27 subjects without cardiovascular disease, who were studied in our laboratory, was $99 \pm 2 \mathrm{~mm}$. $\mathrm{Hg}$, which is essentially identical with the hyperthyroid mean. The mean age of this latter group was 37.1 years, a little above the mean of the thyrotoxics. One cannot conclude from these data whether or not the mean arterial pressure is elevated in hyperthyroidism.

The estimated peripheral vascular resistance, obtained as the quotient of the mean systemic arterial pressure and the cardiac index, and expressed in absolute units per sq. M. of body surface, averaged 18.8 in hyperthyroidism, to be compared with the normal value of 27.2 of Stead and co-workers. This is a highly significant reduction below the normal figure.

The right atrial pressure in hyperthyroidism was not elevated, the mean being $2.5 \mathrm{~mm}$. $\mathrm{Hg}$ against the control value of $2.7 \mathrm{~mm}$. $\mathrm{Hg}$ from the data of Stead. Likewise, the mean hepatic venous pressure in hyperthyroidism, $3.9 \mathrm{~mm}$. $\mathrm{Hg}$, did not differ from our mean control value of $5.6 \mathrm{~mm}$. $\mathrm{Hg}$. The right ventricular pressure in hyperthyroidism, on the other hand, is quite consistently elevated. This is true of both the mean and systolic right ventricular pressures, the average values for which were $15 \pm 1$ and $36 \pm 2 \mathrm{~mm}$. $\mathrm{Hg}$, respectively. The mean normal values for right ventricular pressure in 16 subjects were $22 \pm 1$ $\mathrm{mm}$. $\mathrm{Hg}$ systolic and $10 \pm 1 \mathrm{~mm}$. $\mathrm{Hg}$ mean pressure. The right ventricular diastolic pressure was within normal limits as is evidenced by the normal mean right atrial pressure.

In the pulmonary artery, as in the right ventricle, the systolic and mean pressures were elevated whereas the diastolic pressure was normal. The average values in nine thyrotoxics were: systolic pressure $30 \pm 2 \mathrm{~mm}$. $\mathrm{Hg}$; diastolic pressure $11 \pm 1 \mathrm{~mm}$. $\mathrm{Hg}$; and mean pressure $20 \pm 1$ $\mathrm{mm}$. $\mathrm{Hg}$, to be compared with average figures from 12 controls of systolic pressure $20 \pm 1 \mathrm{~mm}$. $\mathrm{Hg}$; diastolic pressure $11 \pm 1 \mathrm{~mm}$. $\mathrm{Hg}$; and mean pressure $13 \pm 1 \mathrm{~mm}$. Hg. The pulmonary peripheral vascular resistance, as estimated from the quotient of the mean pulmonary arterial pressure and the cardiac index, was not significantly abnormal in the hyperthyroid group, the mean value being
$3.98 \pm 0.33 \mathrm{~mm}$. Hg per L. per min. per sq. M. in comparison with the control mean of $3.44 \pm 0.52$.

The total vascular resistance to blood flow encountered in the splanchnic area may be estimated by the quotient: (mean arterial pressure - hepatic venous pressure) $\div$ (hepatic, or splanchnic, blood flow per sq. M. of body surface). The splanchnic vascular resistance thus calculated is $119 \pm 11$ absolute units in hyperthyroidism and $128 \pm 8$ in the controls, values not significantly different. This result is evident of course in the fact that neither the mean arterial pressure nor the hepatic blood flow differs much from the control values.

\section{DISCUSSION}

The rate of splanchnic metabolism in hyperthyroidism, as judged by oxygen consumption, is increased to a level in excess of the average metabolic rate of the body. A considerably increased splanchnic oxygen extraction is required to accomplish this elevated splanchnic metabolic rate in the face of the essentially normal splanchnic blood flow. Provided all.hepatic cells are using oxygen at the same rate, this high extraction would result in the situation where the most central cells of the hepatic lobule are exposed to considerable anoxia. Thus one might explain why centro-lobular necrosis of the liver is found in certain instances of hyperthyroidism where conditions are such as to $a$ ) further increase splanchnic oxygen consumption, as with fever or exacerbation of the thyrotoxicosis in thyroid storm, or b) compromise the splanchnic blood flow, as with shock or cardiac decompensation. The circulatory findings reported in this paper would not seem to account for the focal necroses and the largely periportal fibroses which are found in some livers from cases of human hyperthyroidism. The situation of an increased splanchnic metabolism coexistent with a normal splanchnic blood flow provides an exception to hypothesis of Roy and Brown (27), Freeman (28), and others that the rate of local tissue metabolism regulates the blood flow through that part.

The finding of the elevated splanchnic oxygen extraction in the presence of a normal hepatic blood flow has been so consistent in cases of thyrotoxicosis that this evidence has been of practical value in several patients, not reported in this paper, in corroborating an uncertain clinical diagnosis of hyperthyroidism. 
It is proper to raise the question, in the face of an elevated cardiac output and a normal splanchnic blood flow, as to where the extra blood pumped by the heart goes. Increased blood flows in skin (15) and skeletal muscle (16) have been demonstrated in hyperthyroidism. Merrill (29) has found the renal blood flow to be elevated in hyperthyroidism unless heart failure supervenes. Scheinberg (30) on the other hand has demonstrated normal cerebral blood flow and cerebral oxygen consumption in thyrotoxicosis. The elevated cutaneous, muscular, and renal blood flows would seem adequate to account for the increase in total cardiac output in the presence of the normal splanchnic and cerebral flows.

The oxygen difference between arterial and mixed venous blood in hyperthyroidism is normal although the splanchnic arteriovenous oxygen difference is increased by about 50 per cent. This necessarily indicates a reduced arteriovenous oxygen difference in some other portion of the body, presumably in areas such as the skin where blood flow is augmented.

The cause of the elevation in systolic and mean pressures in the right ventricle and pulmonary artery in hyperthyroidism is not clear. It should be noted that these pressures are elevated at the same time that the corresponding diastolic pressures are normal. The rise in mean pulmonary arterial pressure is in balance with the increase in pulmonary blood flow (cardiac output) giving calculated pulmonary peripheral vascular resistances with the normal range. In this last respect, the patient with thyrotoxicosis does differ from the normal individual under conditions of exercise, where the pulmonary blood flow can be doubled or trebled without any significant rise in pulmonary arterial pressure (26). Thus, if one can compare the increased pulmonary flows of hyperthyroidism and of exercise in the normal person, it can be said that in the former circumstance there is a failure of the pulmonary vascular bed to open up in order to accommodate the increased flow without a rise in pulmonary arterial and right ventricular pressures. One can only conjecture whether a more rapid ejection of blood from the right ventricle in early systole, as is suggested below, is responsible in any part for the increase in right ventricular and pulmonary arterial systolic pressures.
The normal diastolic pressure in the pulmonary artery would militate against left ventricular failure with elevated pulmonary venous and capillary pressures as the cause of the rise in mean pulmonary arterial pressure. Furthermore, these subjects with hyperthyroidism were maintaining well elevated cardiac outputs in the absence of any of the usual clinical findings of left ventricular decompensation.

It is of interest to note that data thus far available for thyrotoxicosis indicate normal peripheral vascular resistances in the lungs, splanchnic area, and brain (30) in the presence of an overall decrease in peripheral resistance. The normal resistances in the brain and splanchnic area must indicate a considerable reduction in resistance in such sites as the skin.

It is our impression from inspection of the pressure tracings from the right ventricle that the rise in systolic pressure is more abrupt in hyperthyroidism than in the normal state. Provided this situation holds for the left ventricle, the finding can be offered as an explanation for the accentuated first heart sound which is characteristic of hyperthyroidism. The abrupt rise in ventricular pressure at the onset of systole would result in a more forceful closure of the mitral and tricuspid valves. It should be stressed that the stroke volume is essentially normal in thyrotoxicosis and is thus not a factor in either the alteration in right or left ventricular systolic pressure or the accentuated first sound.

\section{SUMMARY AND CONCLUSIONS}

1. The hepatic blood flow in hyperthyroidism is little, if at all, increased in spite of a definitely increased cardiac output.

2. The splanchnic oxygen consumption in hyperthyroidism is elevated even more than is the general metabolic rate in this disease. This is accomplished, in the face of the essentially normal splanchnic blood flow, by an increased oxygen extraction. The latter could easily result in anoxia of the centro-lobular zones of the liver and may well be related to the centro-lobular necrosis found in certain instances of complicated thyrotoxicosis.

3. Hyperthyroidism is associated with an elevation of systolic and mean pressures, but not of diastolic pressures, in the right ventricle and pulmonary artery. These pressure elevations coexist 
with an elevated pulmonary blood flow (cardiac output) and a normal pulmonary peripheral vascular resistance. The cause of the pressure increases is not known; they do not appear to be related to left ventricular failure.

4. The ability of the liver to excrete bromsulphalein is moderately impaired in some, but not all, individuals with hyperthyroidism.

\section{ACKNOWLEDGMENTS}

This work was accomplished with the technical assistance of Miss Leila Holmes, Miss Mamie McLawhorn, Mrs. Juanita M. Clontz, Miss Dorothy Frederick, Miss Eloise Cavin, Miss Regina Frayser, and Mrs. Louise Allen.

\section{BIBLIOGRAPHY}

1. Maddock, W. G., Pedersen, S., and Coller, F. A., Studies of the blood chemistry in thyroid crisis. J. A. M. A., 1937, 109, 2130.

2. Boyce, F. F., and McFetridge, E. M., Studies of hepatic function by the Quick hippuric acid test; thyroid disease. Arch. Surg., 1938, 37, 427.

3. Bartels, E. C., Serum-protein studies in hyperthyroidism. N. England J. Med., 1938, 218, 289.

4. Piper, J., and Poulsen, E., Liver biopsy in thyrotoxicosis. Acta med. Scandinav., 1947, 127, 439.

5. Weller, C. V., Hepatic lesions associated with exophthalmic goiter. Tr. A. Am. Physicians, 1930, 45, 71.

6. Beaver, D. C., and Pemberton, J. deJ., The pathologic anatomy of the liver in exophthalmic goiter. Ann. Int. Med., 1933, 7, 687.

7. Cameron, G. R., and Karunaratne, W. A. E., Liver changes in exophthalmic goitre. J. Path. \& Bact., 1935, 41, 267.

8. Shaffer, J. M., Disease of the liver in hyperthyroidism. Arch. Path., 1940, 29, 20.

9. McIver, M. A., and Winter, E. A., Deleterious effects of anoxia on the liver of the hyperthyroid animal. Arch. Surg., 1943, 46, 171.

10. McIver, M. A., and Winter, E. A., Further studies on increased susceptibility to chloroform poisoning produced in the albino rat by injection of crystalline thyroxin. J. Clin. Invest., 1942, 21, 191.

11. Sealy, W. C., The induction of liver necrosis in rabbits by the combination of experimental hyperthyroidism and Shope papilloma. Ann. Surg., 1941, $113,572$.

12. Sealy, W. C., Role of infection in the pathogenesis of liver necrosis in hyperthyroidism. Ann. Surg., 1942, 116, 851.

13. Fullerton, C. W., and Harrop, G. A., Jr., The cardiac output in hyperthyroidism. Bull. Johns Hopkins Hosp., 1930, 46, 202.

14. Stewart, H. J., and Evans, W. F., The peripheral blood flow in hyperthyroidism. Am. Heart J., 1940, 20, 715.
15. Eichna, L. W., and Wilkins, R. W., Blood flow to the forearm and calf. IV. Thyroid activity: Observations on the relation of blood flow to basal metabolic rate. Bull. Johns Hopkins Hosp., 1941, 68, 512.

16. Abramson, D. I., and Fierst, S. M., Resting peripheral blood flow in the hyperthyroid state. Arch. Int. Med., 1942, 69, 409.

17. Bradley, S. E., Ingelfinger, F. J., Bradley, G. P., and Curry, J. J., The estimation of hepatic blood flow in man. J. Clin. Invest., 1945, 24, 890.

18. Myers, J. D., The hepatic blood flow and splanchnic oxygen consumption of man-their estimation from urea production or bromsulphalein excretion during catheterization of the hepatic veins. J. Clin. Invest., 1947, 26, 1130.

19. Cohn, C., Levine, R., and Streicher, D., The rate of removal of intravenously injected bromsulphalein by the liver and extra-hepatic tissues of the dog. Am. J. Physiol., 1947, 150, 299.

20. Cohn, C., Levine, R., and Kolinsky, M., Hepatic and peripheral removal rates in the dog, for intravenously injected bromsulphalein. Am. J. Physiol., 1948, 155, 286.

21. Myers, J. D., and Hickam, J. B., An estimation of the hepatic blood flow and splanchnic oxygen consumption in heart failure. J. Clin. Invest., 1948, 27,620 .

22. Chapin, M. A., and Ross, J. F., The determination of the true cell volume by dye dilution, by protein dilution, and with radioactive iron. The error of the centrifuge hematocrit. Am. J. Physiol., 1942, 137, 447.

23. Brannon, E. S., Merrill, A. J., Warren, J. V., and Stead, E. A., Jr., The cardiac output in patients with chronic anemia as measured by the technique of right atrial catheterization. J. Clin. Invest., $1945,24,332$.

24. Myers, J. D., Unpublished observations.

25. Stead, E. A., Jr., Warren, J. V., Merrill, A. J., and Brannon, E. S., The cardiac output in male subjects as measured by the technique of right atrial catheterization. Normal values with observations on the effect of anxiety and tilting. J. Clin. Invest., $1945,24,326$.

26. Hickam, J. B., and Cargill, W. H., Effect of exercise on cardiac output and pulmonary arterial pressure in normal persons and in patients with cardiovascular disease and pulmonary emphysema. J. Clin. Invest., 1948, 27, 10.

27. Roy, C. S., and Brown, J. G., The blood pressure and its variations in the arterioles, capillaries, and smaller veins. J. Physiol., 1879-1880, 2, 323.

28. Freeman, N. E., The effect of temperature on the rate of blood flow in the normal and in the sympathectomized hand. Am. J. Physiol., 1935, 113, 384.

29. Merrill, A. J., Personal communication.

30. Scheinberg, P., Cerebral circulation and metabolism in hyperthyroidism. J. Clin. Invest., 1950, 29, 1010. 